\title{
Strain analysis in ferritic filler weldment by using the modified Williamson-Hall method
}

\author{
Mohammad Dani a, , Aziz Khan Jahja a , Parikin a, Andon Insani a , Riza Iskandar b \\ a Center for Science and Technology of Advanced Materials, BATAN Kawasan Puspiptek, Serpong Tangerang 15314, Indonesia \\ b Central Facility for Electron Microscopy (GFE), RWTH Aachen University, Ahornstr. 55,D-52074 Aachen,Germany \\ * Corresponding author: mdani@batan.go.id
}

\section{Article history}

Received 3 October 2017

Accepted 28 November 2017

\begin{abstract}
A strain analysis study of the Fe-Cr-Ni based low carbon steel for welding application prepared by a thermal-induction furnace were performed using a modified Williamson-Hall (MHW) method. Three different models, uniform deformation (UDM), the uniform deformation stress (UDSM), and the the uniform deformation energy density (UDEDM) models. The optimal results showed by calculation result using UDM method indicate that uniform deformation was present on analyzed material. Based on UDM method, the welded material contains smaller grain size than the based materials. The calculated of average microstrain values of $7.6351 \times 10-4$ and $-9.21 \times 10-4$ for based and welded materials respectively suggest different strain phenomena occurs during welding processes. Microstructure analysis by means of transmission electron microscopy reveal that based material consist of grains in 50-100 nm sizes and with planar defects are also detected..
\end{abstract}

Keywords: Nano-structured materials, chemical synthesis, crystal structure, TEM, W-H analysis

\section{INTRODUCTION}

$\mathrm{Fe}-\mathrm{Cr}-\mathrm{Ni}$ based low carbon steels are still the subject of many research activities. They exhibit lower strength but higher ductility/toughness. Typical application may include heat exchanger appliances, automotive and architectural trim (i.e. decorative purposes). Some of research activities are aimed to understand the mechanical and physical properties of non-standard low carbon steels, in which the composition of the steel-alloys does not follow the preset AISI standards [1]. This type of sample composition is also not available before in the free market $[2,3,4]$. Therefore, these samples and their properties represent a state of the art new development in materials technology especially for welding applications.

As welding induces a large amount of strain in the bulk samples [5], systematically study for both based and weld materials need to be performed. Lattice strains are commonly encountered in welded components, because of lattice deformation [6]. This is caused by several factors, such as the thermal expansion effects of welding, the pre-welding fabrication and post-welding treatment cause the strain state to arise in the welded plates and bars. And these various influences may also be the cause of disintegration of the material's structural integrity, because of the ensuing reduced fatigue life or increased susceptibility to environmentally assisted failure mechanisms.[7,8].

One of powerful technique to analysis strain formation of weld materials is by means of Neutron profile analysis. [8]. One of method to analysis strain formation is by using Williamson-Hall (W-H) analysis. This method is a simplified integral breadth method where both size-induced and strain-induced broadening are deconvoluted by considering the peak width as a function of $2 \theta$ [9]. In the present study, $\mathrm{W}-\mathrm{H}$ analysis is employed for estimating crystallite size and lattice strain.

In this present work three modified forms of W-H uniform deformation (UDM), uniform deformation stress (UDSM) and uniform deformation energy density models (UDEDM) were applied [10]. To strengthen the strain analysis, microstructure analysis by means of transmission electron microscopy technique is also presented.

\section{THEORY}

When a sample is subjected to homogenous strain, the peak's angular position will shift to either lower or higher $2 \theta$ values depending on whether a yield- or a tensile-strain is being applied on the sample. On the other hand, an inhomogeneous strain field will cause besides an angular shift also a broadening in the intensity profile. Experimentally, heating and cooling a metallic specimen will induce lattice strain in the specimen. The shift in peak-position is tied to the average strain in the crystal's direction. The peak broadening reveals information on the inhomogeneous strain-field distribution fluctuation [5].The average lattice strain in the crystal direction $[h k l]$, is expressed by:

$$
\varepsilon \mathrm{hkl}=\frac{d-d_{O}}{d_{O}}
$$

Here $d_{o}$ and $d$ are stress-free and stress-induced lattice-distance respectively. In table 3 , the $\varepsilon h k l$ and $d_{h k l}$ values for each treatment phase are presented and compared. The profile broadening induced by inhomogeneous strain-field $e^{2} h k l$ is expressed as:

$$
\beta_{h k l}^{2}=\beta_{o}^{2}+32 \ln 2 \varepsilon^{2}(\tan \theta)^{2}
$$

$\beta_{h k l}^{2}$

is the FWHM of peak broadening and $\beta^{2}$ is the angular dependent instrument resolution, given by the Cagliotti expression [6,7] as follows: 


$$
\beta_{o}^{2}=U_{o}(\tan \theta)^{2}+V_{o}(\tan \theta)+W_{o}
$$

$U_{o}, V_{\mathrm{o}}$, and $W_{\mathrm{o}}$ are the three Gaussian FWHM parameters. Using the RIETAN-refined values of $U_{\mathrm{o}}, V_{\mathrm{o}}$, and $W_{\mathrm{o}}$ presented in table 4 . The significance of the broadening of peaks evidences grain refinement along with the large strain associated with the powder. The instrumental broadening $\left(\beta_{\mathrm{hkl}}\right)$ was corrected, corresponding to each diffraction peak of $73 \mathrm{Fe} 24 \mathrm{Cr} 2 \mathrm{Si} 0.8 \mathrm{Mn} 0.1 \mathrm{Ni}$ material using the relation:

$$
\beta_{h k l}=\left(\beta_{h k l, \text { measured }}^{2}-\beta_{h k l, \text { instrumental }}^{2}\right)^{1 / 2}
$$

When crystals' size is less than $1000 \AA(0.1 \mu \mathrm{m})$, crystals of this size will contribute to a broadening of the Debye rings, the extent of the broadening $\beta_{\mathrm{hkl}}$ and the average nanocrystalline size is given as the Debye-Scherrer's formula;

$$
\mathrm{D}=\frac{\mathrm{K} \lambda}{\beta_{h k l}} \frac{1}{\cos \theta}
$$

where $\mathrm{D}=$ crystalline size, $\mathrm{K}=$ shape factor $(0.9)$, and $\lambda=$ wavelength of neutron radiation $1.8223 \AA$ As. Assuming that the particle size and strain contributions to line broadening are independent to each other and both have a Cauchy-like profile, the observed line breadth is simply the sum of Equations 2 and 3.

$$
\beta_{h k l}=\frac{\mathrm{K} \lambda}{D \cos \theta}+4 \varepsilon \tan \theta
$$

Size and strain in a polycrystalline sample could be separated with the Williamson-Hall method. Williamson-Hall method is used to determine the crystallite size and microstrain in order to make comparison with the results obtained from the whole pattern refinements. It was suggested that the broadening due to size and microstrain can be expressed as [5],

$$
\beta_{h k l} \cos \theta=\frac{\mathrm{K} \lambda}{D}+4 \varepsilon \sin \theta
$$

where $D$ is the crystallite diameter size $(\AA)$ and $\varepsilon$ is the average maximum micro strain. Plotting $\beta_{h k l} \cos \theta$ versus $\sin \theta$, will result in a straight line. In this case, the microstrain is obtained from the slope of the regression line and the intercept with the vertical axis is related to the value of the inverse of the size (nanosize) of the particles. In this case, some of the mechanical effects such as the energy density and the stress of the uniform deformation were taken also considered; Assumption that the Young modulus of the crystal is anisotropic is more in line with reality [9]. In the generalized Hook's law the stress is linearly proportional to the and strain, and in this case the constant of proportionality is the modulus of elasticity or Young modulus, denoted by E. Then the Williamson-Hall equation is modified by substituting the value of $\varepsilon$ in Equation 7; one obtain

$$
\beta_{h k l} \cos \theta=\frac{\mathrm{K} \lambda}{L}+4 \sin \theta \frac{\sigma}{E h k l}
$$

$E_{\mathrm{hkl}}$ is Young's modulus in the direction perpendicular to the set of the crystal lattice plane $(h k l)$.

From the slope of the linear plot between $4 \sin \theta / E_{h k l}$ and $\beta_{h k l}$, the uniform stress - and from the intercept the crystallite size D can be calculated. The strain can be measured if $E_{\mathrm{hkl}}$ of cubic $73 \mathrm{Fe} 24 \mathrm{Cr} 2 \mathrm{Si} 0.8 \mathrm{Mn} 0.1 \mathrm{Ni}$ is known. For samples with a cubic crystal phase, the relation between the Young's modulus $E_{\mathrm{hkl}}$ to their elastic compliances $S_{\mathrm{ij}}$ is stated as [5,7];

$$
\frac{1}{S_{11}-2 S A_{h k l}}
$$

With the degree of anisotropy given as,

$$
A h k l=\frac{h^{2} k^{2}+h^{2} l^{2}+l^{2} k^{2}}{h^{2}+k^{2}+l^{2}}
$$

and

$$
S=1 / 2\left(S_{11}-S_{12}-S_{44}\right)
$$

The values of the $S_{11}, S_{12}$, and $S_{44}$ elastic compliances of Fe iron are $0.80 \times 10^{-11},-0.28 \times 10^{-11}$ and $0.86 \times 10^{-11} \mathrm{~Pa}^{-1}$, respectively [5]. According to Hooke's law, the energy density $\boldsymbol{e}$ (energy per unit volume) as a function of strain is $\boldsymbol{e}=\varepsilon^{2} E_{\mathrm{hk}} / 2$. Therefore the uniform deformation energy density (UDEDM) can be calculated from the slope of the linear graph in the $\beta$ hkl $\cos \theta$ vs. $4 \sin \theta\left(2 / E_{\mathrm{hkl}}\right)^{1 / 2}$ plot, by first modifying Equation 6 to the form,

$$
\beta_{h k l} \cos \theta=\frac{\mathrm{K} \lambda}{L}+4 \sin \theta \sqrt{\frac{2 e}{E h k l}}
$$

where $\boldsymbol{e}$ is the energy density (energy per unit volume). The lattice strain can be calculated by knowing the Young moduli $E_{\mathrm{hkl}}$ values of the sample

\section{MATERIALS AND METHODS}

\section{Materials}

The low carbon stainless steel consists primarily of base materials such as of ferro scrap, ferro-chrome, ferro-manganese, ferro-silicon; all of them are in granular form and are minerals products obtained from domestic mines. Details of the chemical composition of both base and filler materials are listed in Table 1.

Table 1. The Chemical composition of $73 \mathrm{Fe} 24 \mathrm{Cr} 2 \mathrm{Si} 0.8 \mathrm{Mn} 0.1 \mathrm{Ni}$ low carbon steel.

\begin{tabular}{cc}
\hline Element & \%wt. \\
\hline $\mathrm{Fe}$ & 72.97 \\
$\mathrm{Ni}$ & 0.12 \\
$\mathrm{Cr}$ & 23.71 \\
$\mathrm{Mn}$ & 0.82 \\
$\mathrm{Si}$ & 2.02 \\
$\mathrm{C}$ & 0.26 \\
$\mathrm{Al}$ & 0.01 \\
$\mathrm{~S}$ & 0.01 \\
$\mathrm{P}$ & 0.02 \\
$\mathrm{~V}$ & 0.06 \\
$\mathrm{Ti}$ & 0.01 \\
$\mathrm{Sn}$ & 0.01 \\
$\mathrm{Nb}$ & 0.01 \\
\hline
\end{tabular}

The base metal is the $73 \mathrm{Fe} 24 \mathrm{Cr} 2 \mathrm{Si} 0.8 \mathrm{Mn} 0.1 \mathrm{Ni}$ (in \%wt.) stainless steel and the filler metal was also ferritic type stainless steel. The samples, as seen in Figure 1, have dimension of $200 \times 10 \times 5 \mathrm{~mm}^{3}$, and designated for base and filler-welded at $350^{\circ} \mathrm{C}$ respectively. The sample preparation follows the common standard metallographic procedure [12]. Welding processes were performed using the manual Gas Tungsten Arc Welding (GTAW) technique. Details of welding parameters are given in Table 2 .

For the neutron diffraction measurement and pre-welding preparation the ferritic samples are prepared by mechanical method into bulk shape of approximately $1.5 \times 1.5 \mathrm{~cm}^{2}$ in wide-thick and $60.0 \mathrm{~cm}$ in length and the surface was mechanically grinded into flat surface and polished-cleaning to remove any surface oxides and contaminants. 


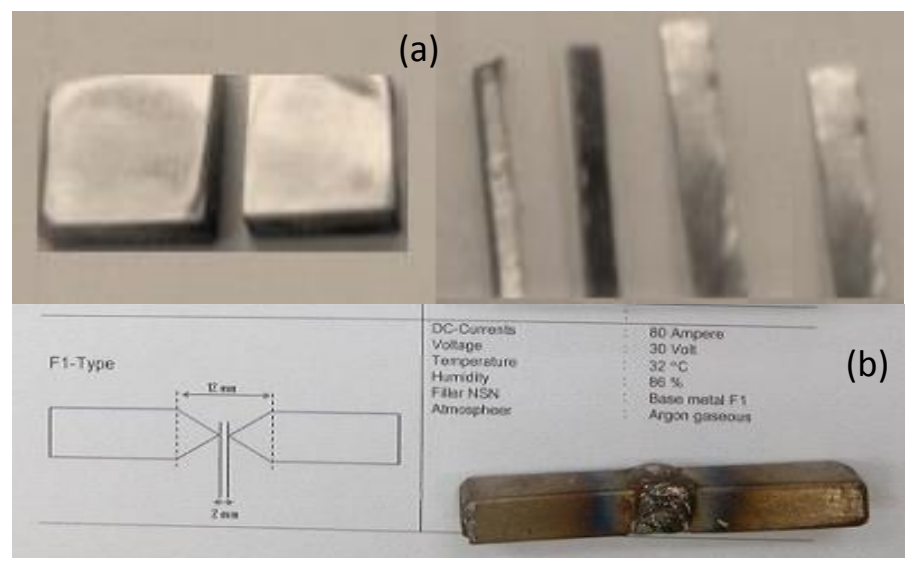

Fig. 1 (a) The Fe-Cr-Ni base and the filler welded materials, (b) Welding schema and $\left(60 \times 15 \times 15 \mathrm{~mm}^{3}\right)$ dimension of weld specimens used in neutron diffraction measurements.

Table 2. TIG-weld parameters for $73 \mathrm{Fe} 24 \mathrm{Cr} 2 \mathrm{Si} 0.8 \mathrm{Mn} 0.1 \mathrm{Ni}$ alloy sample.

\begin{tabular}{lll}
\hline TIG-weld Parameters & & \\
\hline Welding Type & $\vdots$ & GTAW \\
Dimension & $\vdots$ & $50 \times 15 \times 15 \mathrm{~mm}^{3}$ \\
Atmospheer & $\vdots$ & Argon \\
Current & $\vdots$ & $80 \mathrm{~A}$ \\
Voltage & $\vdots$ & $30 \mathrm{~V}$ \\
Speed & $:$ & $60 \mathrm{~mm} / \mathrm{min}$ \\
\hline
\end{tabular}

\section{Apparatus and Methods}

Strain and strain analysis were performed by means neutron powder diffraction techniques. High resolution powder diffractometer (HRPD) spectrometer from located at Neutron Scattering Laboratory attached to the G.A.S. Siwabessy Research Reactor at BATAN in Serpong was used. The neutron wavelength of $\lambda=1.8223 \AA$ was determined from calibration measurements of four diffraction peaks from a silicon standard powder sample, the step counting mode with an incremental step of $0.05^{\circ}$ was used. The focused ion beam (FIB) technique has been employed to prepare lamella for transmission electron microscopy (TEM) analysis. A single beam Strata 205 from FEI was used to prepare the lamella [11]. The TEM analysis were performed on Zeiss Libra 200 FE, a Schottky field emission TEM operates at $200 \mathrm{keV}$. The microscope equipped within column corrected omega filter, a high angle angular dark field (HAADF) and energy dispersive spectrometer (EDS) detectors from fischione and bruker respectively

\section{RESULTS AND DISCUSSION}

\section{Neutron diffraction analysis}

The Neutron Diffraction pattern of the base material as shown in Figure 2 is having a cubic structure with no extra diffraction peaks belongs to secondary phase. The peaks' intensity is sharp and narrow, confirming that the sample is of high quality with good crystallinity and fine grain size. Using HRPD data, lattice parameters were refined and the results presented in Table 3.

Table 3. Refined neutron diffraction structural Parameters of Fe-Cr-N alloy(base and welded with filler condition).

\begin{tabular}{c|cccc}
\hline $\begin{array}{c}\text { Phase } \\
\alpha-\mathrm{Fe}\end{array}$ & $\begin{array}{c}\text { Lattice } \\
\text { parameter } \\
\left.a(\AA)^{*}\right)\end{array}$ & $\begin{array}{c}\mathrm{R}_{\mathrm{wp}} \\
(\%)\end{array}$ & $\begin{array}{c}\mathrm{R}_{\mathrm{p}} \\
(\%)\end{array}$ & $\begin{array}{c}\mathrm{R}_{\mathrm{e}} \\
(\%)\end{array}$ \\
\hline Condition & $2.8745(4)$ & 126.0 & 74.43 & 27.05 \\
\hline base & $2.8689(3)$ & 90.80 & 47.80 & 19.60
\end{tabular}

$\$$ SG. Fm3m (vol. I-225);1601 data points, 4 reflections (110), (200), (211) and (220)

*) The number inside parentheses indicates the uncertainty of the last significant digit

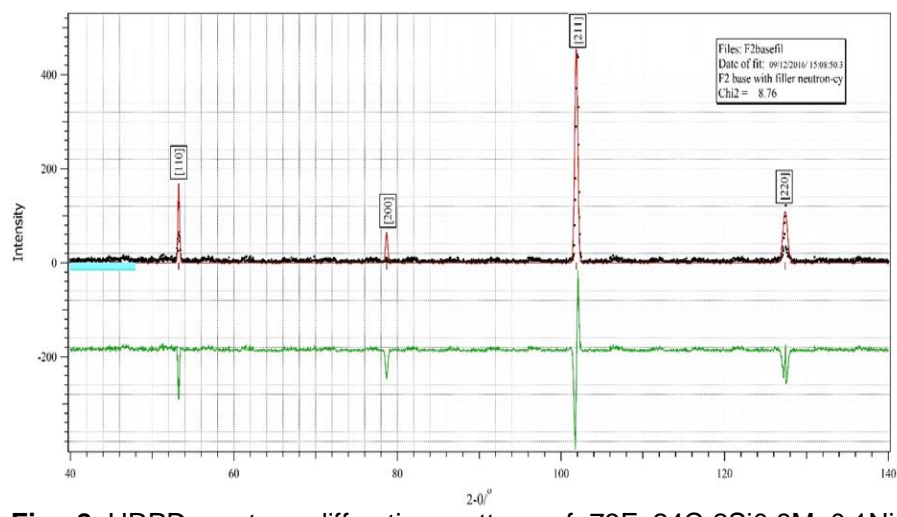

Fig. 2 HRPD neutron diffraction pattern of $73 \mathrm{Fe} 24 \mathrm{Cr} 2 \mathrm{Si} 0.8 \mathrm{Mn} 0.1 \mathrm{Ni}$ base material.

The neutron diffraction pattern of the filler-welded material (Figure 3) shows additional peaks from secondary phase as addition to the matrix which could form filler material in the weldment zone.

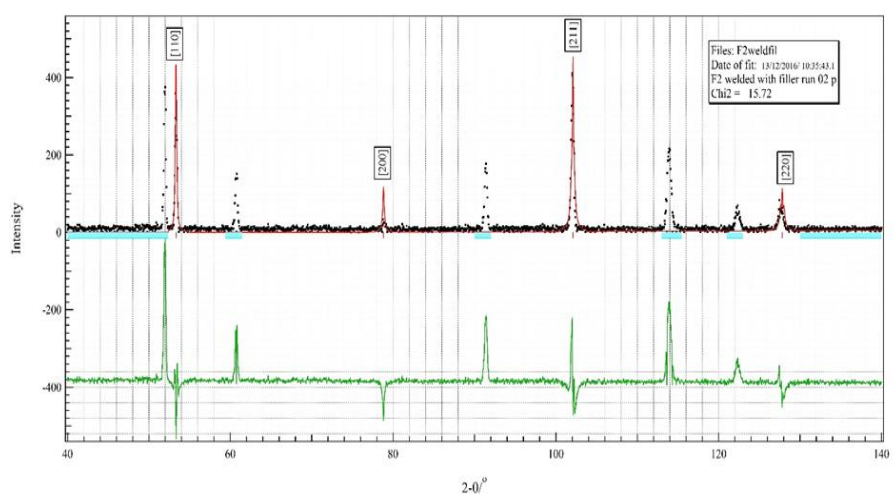

Fig. 3 HRPD neutron diffraction pattern measured in weldment zone of 73Fe24Cr2Si0.8Mn0.1Ni filler-welded sample.

Further analysis using Rietveld refinemet procedures were applied by excluding additional peaks from secondary phase. The results are presented in Table 1. The refinement results are also used to calculate the strain-free and strain-induced lattice-distances, $d_{o}$ and $d$, which are used in the calculation of $e_{h k l}$ as presented in Table 4.

Table 4 Comparison of average lattice strain $e_{h k l}$ and $d_{h k l}$ values for the base and filler-welded samples") and Comparison of Relative Intensity of Major Peaks and FWHM.

\begin{tabular}{cccc}
\hline \multirow{2}{*}[hkl]{} & Base & \multicolumn{2}{c}{ Filler-welded } \\
\cline { 2 - 4 } & $d_{h k l, 0}(\AA)$ & $d_{h k l}(\AA)$ & $e_{h k l} \times 10^{-3}$ \\
\hline$[110]$ & $2.032598(4)$ & $2.028566(4)$ & $1.9837(5)$ \\
{$[200]$} & $1.437264(3)$ & $1.424413(2)$ & $1.9836(2)$ \\
{$[211]$} & $1.173521(2)$ & $1.171193(2)$ & $1.9838(2)$ \\
{$[220]$} & $1.016299(2)$ & $1.014283(1)$ & $1.9836(7)$ \\
\cline { 2 - 3 } & & Average & $1.9836(3)$ \\
\hline
\end{tabular}

*) The number inside parentheses indicates the uncertainty of the last significant digit.

The three Gaussian FWHM ( $\beta_{\text {hkl }}$ ) parameters, $U_{o}, V_{\mathrm{o}}$, and $W_{\mathrm{o}}$, for both the base and the filler-welded $73 \mathrm{Fe} 24 \mathrm{Cr} 2 \mathrm{Si} 0.8 \mathrm{Mn} 0.1 \mathrm{Ni}$ samples, are shown in Table 5. These parameters are used to calculate the FWHM ( $\left.\beta_{\mathrm{hkl}}\right)$ values using equations (2) and (3) as presented in Table 6.

Table 5. Gaussian FWHM $\left(\beta_{\mathrm{hkl}}\right)$ parameters $U_{0}, V_{0} W_{0}$

\begin{tabular}{cccc}
\hline Samples & $U_{o}$ & $V_{\circ}$ & $W_{\circ}$ \\
\hline Base & $0.104123(3)$ & $-0.0104910(5)$ & $0.035367(3)$ \\
Welded with filler & $0.008875(4)$ & $-0.0076180(1)$ & $0.050610(0)$ \\
\hline
\end{tabular}


Table 6. FWHM $\left(\beta_{\mathrm{hk}}\right)$ from Rietveld refinement sresults of base- and fillerwelded $73 \mathrm{Fe} 24 \mathrm{Cr} 2 \mathrm{Si} 0.8 \mathrm{Mn} 0.1 \mathrm{Ni}$ sample.

\begin{tabular}{ccccc}
\hline$[h \mathrm{kl}$ & $\begin{array}{c}\text { Relative } I_{0} \\
\text { (counts) } \\
\text { base }\end{array}$ & $\begin{array}{c}\text { fwhm } \\
\left(\beta_{\mathrm{hkl}}\right) \\
(\mathrm{rad}) \\
\text { base } \\
\times 10^{-3}\end{array}$ & $\begin{array}{c}\text { Relative } I_{o} \\
\text { (counts) } \\
\text { welded with } \\
\text { filler }\end{array}$ & $\begin{array}{c}\text { fwhm }\left(\beta_{\mathrm{hkl}}\right) \\
(\mathrm{rad}) \\
\begin{array}{c}\text { Welded } \\
\text { with filler } \\
\times 10^{-3}\end{array}\end{array}$ \\
\hline$[110]$ & 37000 & 3.7441 & 65854 & 4.1409 \\
{$[200]$} & 10300 & 3.6994 & 12200 & 5.4283 \\
{$[211]$} & 100000 & 3.6824 & 100000 & 7.4761 \\
{$[220]$} & 20200 & 3.7776 & 35350 & 1.1586 \\
\hline
\end{tabular}

Strain analysis using the modified Williamson-Hall plot

In Table 7 below the Young moduli $E_{\mathrm{hkl}}$ calculated using equations (9-11) are presented.

Table 7. The Young moduli $E_{\mathrm{hkl}}$ calculated using equations (9-11).

\begin{tabular}{ccccc}
\hline$h k l$ & $(110)$ & $(200)$ & $(211)$ & $(220)$ \\
\hline$E_{h k l}(\mathrm{GPa})$ & 144.93 & 125.00 & 212.77 & 277.8 \\
\hline
\end{tabular}

Using equations (1-11) the various mechanical properties of $73 \mathrm{Fe} 24 \mathrm{Cr} 2 \mathrm{Si} 0.8 \mathrm{Mn} 0.1 \mathrm{Ni}$ nanoparticles such as mean particle size obtained from direct TEM measurements and from neutron diffraction (HRPD) peak broadening and the strain associated with the base and filler-welded $73 \mathrm{Fe} 24 \mathrm{Cr} 2 \mathrm{Si} 0.8 \mathrm{Mn} 0.1 \mathrm{Ni}$ samples at $450^{\circ} \mathrm{C}$ due to lattice deformation could be calculated and plotted according to different Williamson-Hall modified models, namely, uniform deformation model (UDM), the uniform deformation stress model (UDSM), and the uniform deformation energy density model (UDEDM.

The Williamson-Hall plot using the UDM method for the base and the filler-welded $73 \mathrm{Fe} 24 \mathrm{Cr} 2 \mathrm{Si} 0.8 \mathrm{Mn} 0.1 \mathrm{Ni}$ sample is presented in Figure 4 and Figure 5 below.

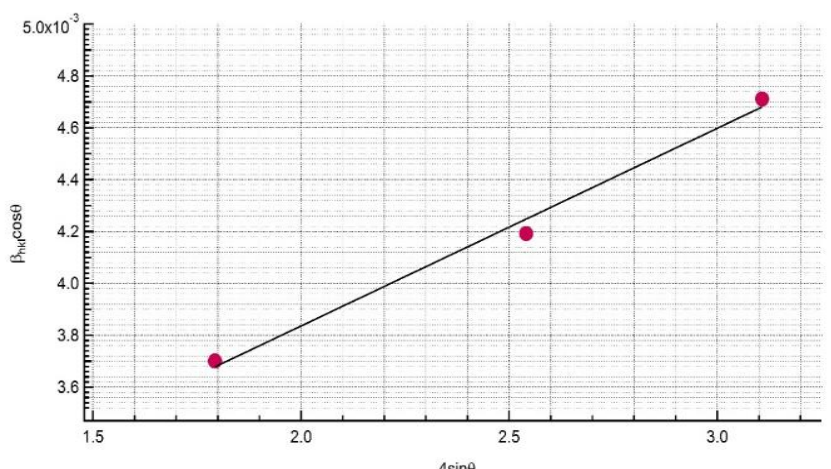

Figure 4. The modified Williamson-Hall plot using the UDM mode obtained by using profile fitting of the neutron diffraction pattern of a base 73Fe24Cr2Si0.8Mn0.1Nibar. The straight regression lines are obtained by least-square method.

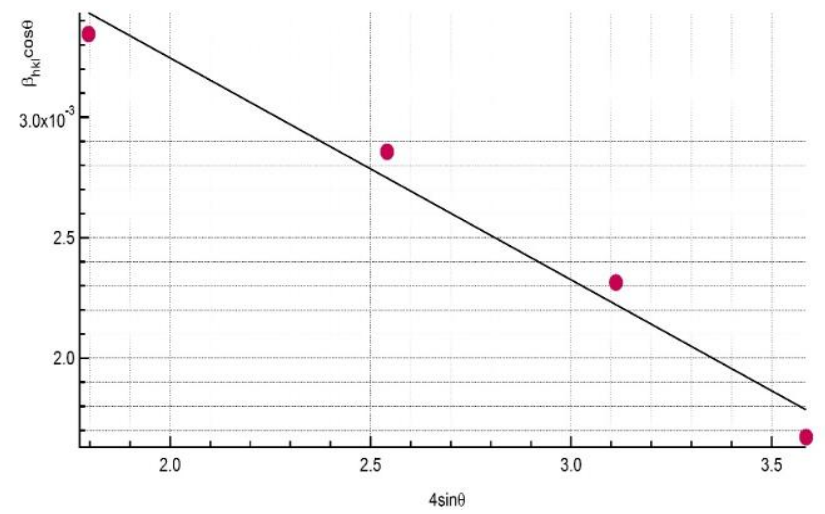

Figure 5. The modified Williamson-Hall plot using the UDM mode obtained by using profile fitting of the neutron diffraction pattern in the $\mathrm{HAZ}$ region of a filler-welded $73 \mathrm{Fe} 24 \mathrm{Cr} 2 \mathrm{Si} 0.8 \mathrm{Mn} 0.1 \mathrm{Nibar}$. The straight regression lines are obtained by least-square method.
The Williamson-Hall plot using the UDSM method for the base and the filler-welded $73 \mathrm{Fe} 24 \mathrm{Cr} 2 \mathrm{Si} 0.8 \mathrm{Mn} 0.1$ Nisample is presented in Figure 6 and Figure 7 below.

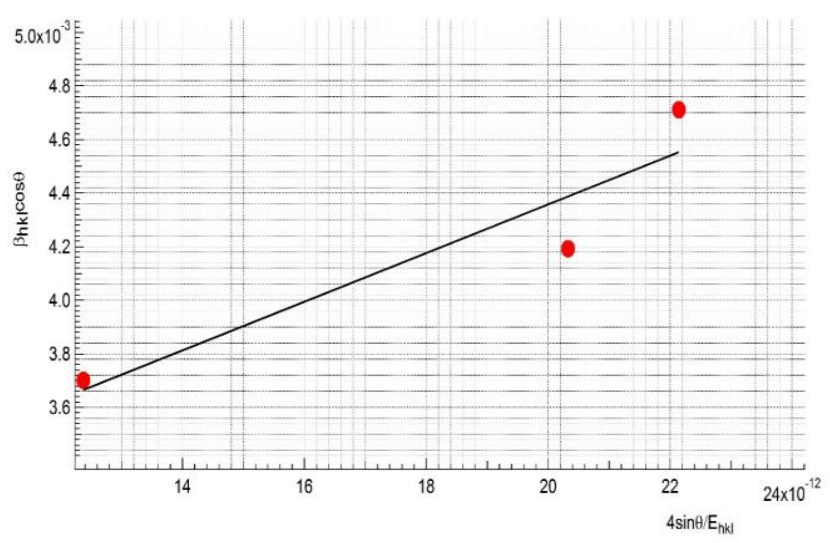

Figure 6. The modified Williamson-Hall plot using the UDSM model obtained by using profile fitting of the neutron diffraction pattern of a base 73Fe24Cr2Si0.8Mn0.1Nibar. The straight regression lines are obtained by least-square method.

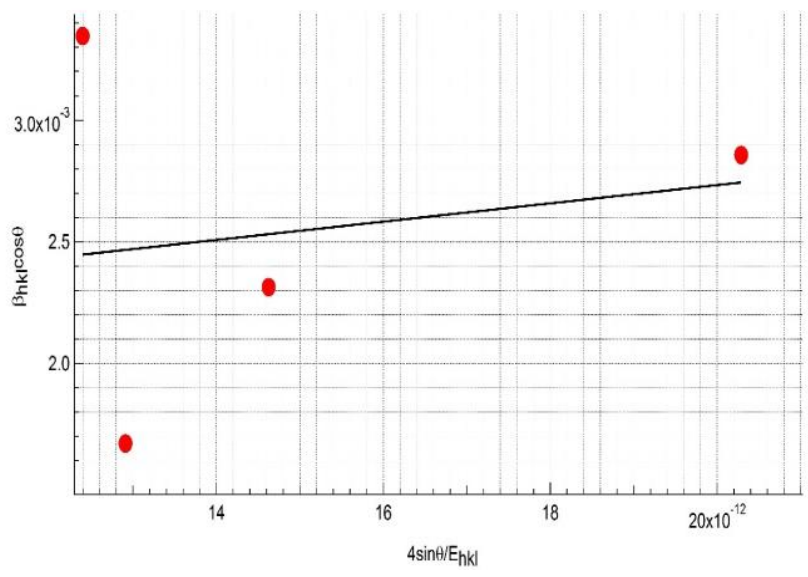

Figure 7. The modified Williamson-Hall plot using the UDSM model obtained by using profile fitting of the neutron diffraction pattern in the $\mathrm{HAZ}$ region of a filler-welded $73 \mathrm{Fe} 24 \mathrm{Cr} 2 \mathrm{Si} 0.8 \mathrm{Mn} 0.1 \mathrm{Nibar}$. The straight regression lines are obtained by least-square method.

The Williamson-Hall plot using the UDEDM method for the base and the filler-welded $73 \mathrm{Fe} 24 \mathrm{Cr} 2 \mathrm{Si} 0.8 \mathrm{Mn} 0.1$ Nisample is presented in Figure 8 and Figure 9 below.

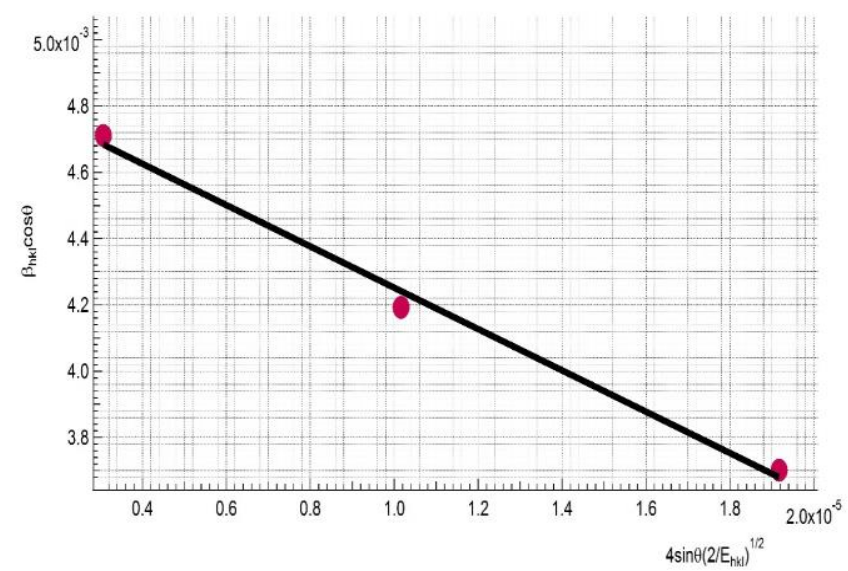

Figure 8. The modified Williamson-Hall plot using the UDEDM model obtained by using profile fitting of the neutron diffraction pattern of a base 73Fe24Cr2Si0.8Mn0.1Nibar. The straight regression lines are obtained by least-square method. 


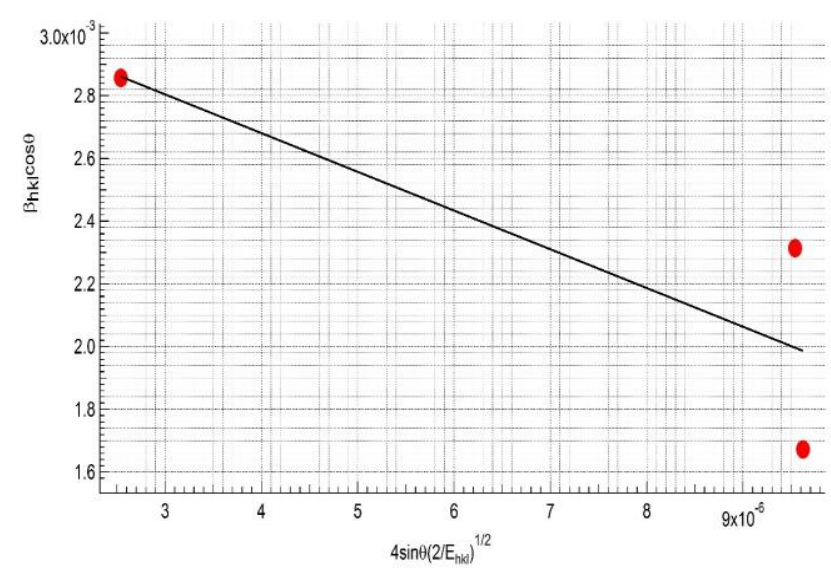

Figure 9. Williamson-Hall plot using the UDEDM plot, obtained by using profile fitting of the neutron diffraction pattern in the HAZ region of a fillerwelded $73 \mathrm{Fe} 24 \mathrm{Cr} 2 \mathrm{Si} 0.8 \mathrm{Mn} 0.1 \mathrm{Ni}$ bar. The straight regression lines are obtained by least-square method.
By comparing the values of average crystallite size obtained from UDM, UDSM, and UDEDM, it was found that the values are not at all similar, implying that the inclusion of strain in various forms has a very large effect on the average crystallite size $73 \mathrm{Fe} 24 \mathrm{Cr} 2 \mathrm{Si} 0.8 \mathrm{Mn} 0.1 \mathrm{Ni}$ alloy particles $[6,12]$. For the base $73 \mathrm{Fe} 24 \mathrm{Cr} 2 \mathrm{Si} 0.8 \mathrm{Mn} 0.1 \mathrm{Ni}$ sample, the largest value of crystallite size is found from the UDM method (71.04 $\mathrm{nm}$ ), and decreases for the USDM and the UDEDM method, which is $64.53 \mathrm{~nm}$ and $33.64 \mathrm{~nm}$ respectively. In the weldment region of the filler-welded sample, all three methods predict that the crystallite size woul be altered as a result of welding. The UDM method predicts that the crystallite size D would decrease $(32.24 \mathrm{~nm})$, whereas both the USDM and the UDEDM method predict that D would increase to 82.67 $\mathrm{nm}$ and $51.69 \mathrm{~nm}$ respectively, so there is a considerable change in the grain size after welding. But these results are consistent with the premise that only grains with sizes $\leq 0.1 \mu \mathrm{m}$ would contribute to profile broadening. However, the energy density value $\boldsymbol{e}$ could not be evaluated from the UDEDM method since the slope of the linear plot is negative, and therefore has no real physical meaning. Therefore this method may not be valid in this case of massive bulk materials.

Table 8. The Geometric Parameters of 73Fe24Cr2Si0.8Mn0.1Ni steel obtained form modified Williamson-Hall method.

\begin{tabular}{c|cc|ccc|ccc}
\hline Method & \multicolumn{3}{|c|}{ UDM } & \multicolumn{3}{c|}{ USDM } & \multicolumn{2}{c}{ UDEDM } \\
\hline Parameters & $\mathrm{D}(\mathrm{nm})$ & $\varepsilon$ & $\begin{array}{c}\mathrm{D} \\
(\mathrm{nm})\end{array}$ & $\begin{array}{c}\Sigma \\
(\mathrm{MPa})\end{array}$ & $\varepsilon$ & $\mathrm{D}(\mathrm{nm})$ & $\begin{array}{c}e \\
\left.(\mathrm{kJm})^{-3}\right)\end{array}$ \\
\hline Base & 71.04 & $7.6351 \times 10^{-4}$ & 64.53 & 90.83 & $4.9364 \times 10^{4}$ & 33.64 & - \\
Filler-welded & 32.24 & $-9.21 \times 10^{-4}$ & 82.67 & 37.48 & $2.037 \times 10^{-4}$ & 51.69 & - \\
\hline
\end{tabular}

\section{Microstructure analysis from transmission electron microscopy data}

Figure 10 shows Bright-Field TEM image of Fe-Cr-Ni sample taken from area close to the surface. The elemental analysis from other report at reference of the work of Parikin et.al revealed the large of $\mathrm{Al}_{2} \mathrm{O}_{3}$ grain formed inside the matrix.A thin layer of $\mathrm{SiO}_{2}$ formed at the matrix-alumina interface. TEM Bright-field image shows high deformations and defects presence on the matrix (Figure 10.a). These defects are also found at oxide - precipitates interface. EDS-analysis identified the precipitate as $\mathrm{Cr}$-carbide precipitate [12].

It was observed that two layers of dense $\mathrm{Al}_{2} \mathrm{O}_{3}$ scale with a total thickness of 200 to $300 \mathrm{~nm}$. Therefore, in this case, lattice strain in the $73 \mathrm{Fe} 24 \mathrm{Cr} 2 \mathrm{Si} 0.8 \mathrm{Mn} 0.1 \mathrm{Ni}$ sample bulk could well be caused by the presence of an excess volume of dislocation grain boundaries [8]. The dimension of the grains as is evident from the TEM images somehow matches the order of magnitude of the size of the crystallite D presented in Table 8, which is bigger than $100 \mathrm{~nm}$.

The presence of microcracks (overlapping layers) on the precipitates was also observed in the surface. As can be seen on Figure 10.b, the overlapping layers developed on interface of chromia precipitate causing the strains in materials. Additional magnification image of selected area shows that overlapping layers also present dislocation at the $\mathrm{Al}_{2} \mathrm{O}_{3}$-matrix interface.

Higher magnification images of selected areas (marked by rectangular A1 and A2) revealed high deformations and defects presence on the matrix as seen in figure 10(b) and (c) respectively. On figure 10 (b), diffraction contrast, which indicates different crystal orientation, appears also in layer forms at the alumina interface. Moreover, $\mathrm{SiO}_{2}$ thin layer approximately $100 \mathrm{~nm}$ thick, which was detected by EDX analysis, appears as amorphous layer. Higher magnification image of area 2, where a precipitate formed, probably $\mathrm{Cr}-\mathrm{C}$ based on EDX analysis, shows similar condition with area 1. On contrast with the matrix, diffraction contrast revealed that the precipitates is almost free from defects. Highly defects and dislocation grain boundaries formed in the matrix could be the cause of the lattice strain in the $73 \mathrm{Fe} 24 \mathrm{Cr} 2 \mathrm{Si} 0.8 \mathrm{Mn} 0.1 \mathrm{Ni}$ sample bulk [8].
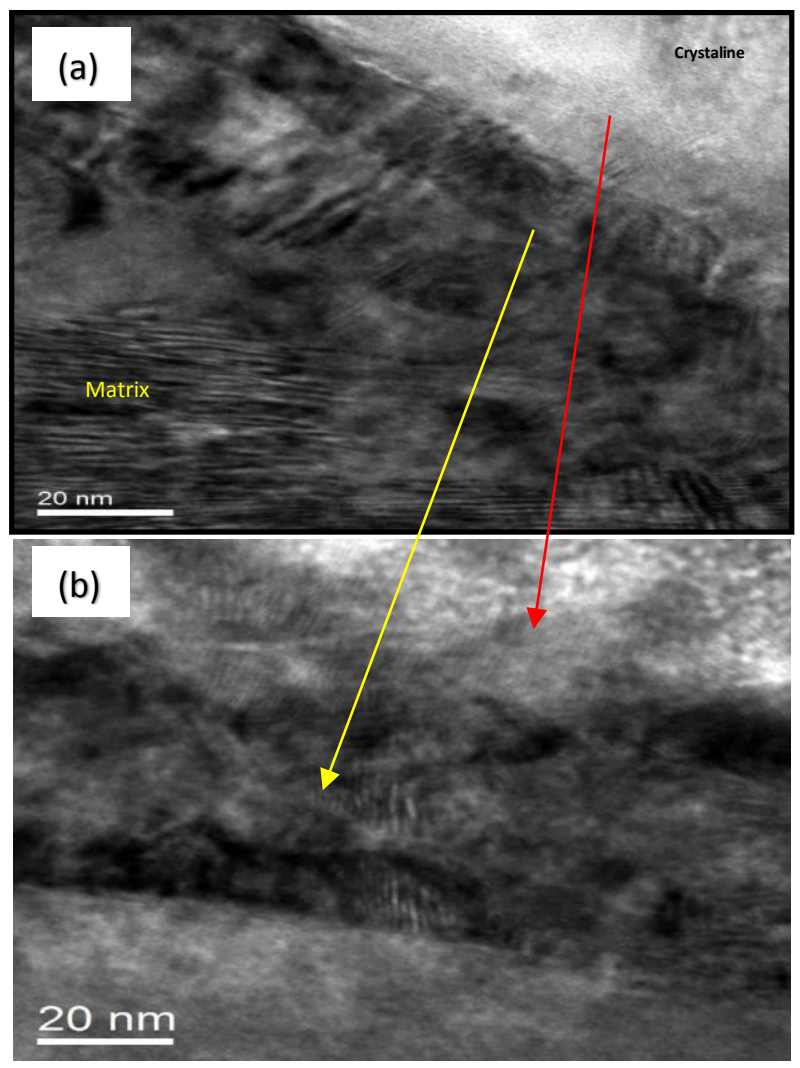

Figure 10. A higher magnification of TEM Bright-Field image on the 73Fe24Cr2Si0.8Mn0.1 Ni base sample to show deformation and defects. 


\section{CONCLUSION}

A new low carbon sample $73 \mathrm{Fe} 24 \mathrm{Cr} 2 \mathrm{Si} 0.8 \mathrm{Mn} 0.1 \mathrm{Ni}$ was synthesized and prepared as base and welded specimens. Both BF TEM analysis and High-resolution powder neutron diffraction analysis are carried out on these samples. Based upon the deep and broad intensity Rietveld analysis of the neutron diffraction experimental data presented, it is observed that the new Low Carbon alloy $73 \mathrm{Fe} 24 \mathrm{Cr} 2 \mathrm{Si} 0.8 \mathrm{Mn} 0.1 \mathrm{Ni}$ is a typical example of the dependence of average lattice strain $e h k l$ on a diffraction plane $[h k l]$ caused by an elastic anisotropy of the crystal. The average value of $4.396(3) \times 10^{-4}$ for the average lattice strain (microstrain) $e_{h k l}$ has been observed in the rolled $73 \mathrm{Fe} 24 \mathrm{Cr} 2 \mathrm{Si} 0.8 \mathrm{Mn} 0.1 \mathrm{Ni}$ sample. Higher resolution analysis by means TEM revealed the presence of high defects formation on matrix which could explain the lattice strain measurement results that is bigger than $100 \mathrm{~nm}$. On the other hand, an angular shift and a broadening in the intensity profile for all diffraction planes as an evidence of an inhomogeneous strain field were observed in the weldment area of $73 \mathrm{Fe} 24 \mathrm{Cr} 2 \mathrm{Si} 0.8 \mathrm{Mn} 0.1 \mathrm{Ni}$ samples. Evidence of the plane dependence of the strain and microstrain necessitates that this study should be continued with neutron diffraction internal stress measurement using the DN1 Powder diffractometer.

\section{ACKNOWLEDGEMENT}

The authors would like to express his gratitude to Mr. Gunawan, head of PSTBM-BATAN, and Dr. Abu-Khalid Rivai head of BSBMPSTBM and Dr. Eng. Iwan Sumirat head of BTBN-PSTBM for their continuing valuable support for this research project in the fiscal year of 2016 and the conducive research climate, which facilitates both the continuation and the finishing of this program at PSTBM-BATAN. The authors also wish to thank Mr. Herry Mugiraharjo from BTBN-PSTBM for the neutron HRPD measurement

\section{REFERENCES}

[1] B. A. Pint, K. A. Terrani, M. P. Brady, T. Cheng, J. R. Keiser. (2013). High temperature oxidation of fuel cladding candidate materials in steamhydrogen environments. J. Nucl. Mater., 440(1), 420-427.

[2] A. K. Jahja (2010). Ferritic stainless steel synthesis from mining materials, In Evvy Kartini, B. V. R. Chowdari, Aziz Khan Jahja, S. Selvasekarapandian, Tutun Nugraha, Junichiro Mizusaki, Sudaryanto, S. J. Kennedy, Heri Jodi. Proceedings of the ICMST 2010. Paper presented at International Conference on Materials Science \& Technology, Serpong (61-68). Serpong: PTBIN-BATAN \& MRS-INA.

[3] T. Darwinto and A.K. Jahja. (2010). Microstructure and crystal structure analysis of F1 ferritic steel. Indonesian Journal of Materials Science, 11 (3), 202-206.

[4] K. A. Terrani, B. A. Pint, Y. -J. Kim, K. A. Unocic, Y. Yang, C. M. Silva, H. M. Meyer, R. B. Rebak. (2016). Uniform corrosion of FeCrAl alloys in LWR coolant environments. J. Nucl. Mat., 479, 36-47.

[5] Noyan, Ismail C., Cohen, Jerome B. (1987). Residual Stress: Measurement by Diffraction and Interpretation, Springer Verlag, New York.

[6] C. -H. Cho, S. -G. Lee, T. -H. Lee, J. Lee. (2013). Fabrication and electrical properties of $\mathrm{YBa} 2 \mathrm{Cu} 3 \mathrm{O} 7-\mathrm{x}$ thin film prepared by sol-gel method for uncooled infrared detectors. J. Ceram. Process. Res., 14(3), 436-439.

[7] S. I. Talabi, O. B. Owolabi, J. A. Adebisi, T. Yahaya. (2014). Adv. Prod Eng. Management (APEM), 9(4), 181-186.

[8] A. N. Ezeilo and G. A. Webster. (1999). Advances in neutron diffraction for engineering residual stress measurements. Textures and Microstructures, 33, 151-171.

[9] F. G. Kevin, N. G. Maxim, Y. Yukinori, L. S. Lance. (2014). Deformation behavior of laser welds in high temperature oxidation resistant $\mathrm{Fe}-\mathrm{Cr}-\mathrm{Al}$ alloys for fuel cladding applications. J. Nucl. Mat. 454, 352-358.

[10] V. D. Mote, Y. Purushotham, B.N. Dole. (2012). Williamson-Hall analysis in estimation of lattice strain in nanometer-sized $\mathrm{ZnO}$ particles. Journal of Theoretical and Applied Physics. Retrieved fromhttp://www.jtaphys.com/content/2251-7235/6/1/6.

[11] H. Dai, J. A. Francis, H. J. Stone, H. K. D. H. Bhadeshia, and P. J. Withers (2008). Characterizing Phase Transformations and Their Effects on Ferritic Weld Residual Stresses with X-Rays and Neutrons. Metall. Mater Trans. A, 39(13), 3070-3078.
[12] M. Dani, P. Untoro, T. Y. S. P. Putra, Parikin, J. Mayer and A. Dimyati. (2015). Transmission Electron Microscopy Characterization of HighTemperatur Oxidation of Fe-20Cr-5Al Alloy Prepared by Focused Ion Beam Technique . Makara J. Technol. 19(2), 85-89.

[13] Parikin, M. Dani, A. K. Jahja, R. Iskandar and J. Mayer. (2017). Crystal Structure Investigation of Ferritic $73 \mathrm{Fe} 24 \mathrm{Cr} 2 \mathrm{Si} 0.8 \mathrm{Mn} 0.1 \mathrm{Ni}$ Steel for Multipurpose Structure Material Applications. IJTech, 8(5), 1-6. 